\title{
Investigation and Analysis on the Construction Situation of "Three Links and Two Platforms" of Education for Nationalities in Yunnan Province in China
}

\author{
Zhao Zhilin", Gan Jianhou',a \\ ${ }^{1}$ College of Tourism and Geographical Sciences and College of Adult Education, Yunnan Normal University, Kunming, Yunnan, China \\ ${ }^{2}$ Key Laboratory of Educational Informatization for Nationalities, Yunnan Normal University, Kunming, Yunnan, China
}

\begin{abstract}
Three Links and Two Platforms", which refers to schools links to ICTs, high-quality resource of class links to ICTs, people links to ICTs, public service platform for educational resources and public service platform for educational management, has played a crucial role in improving the educational equality in minority areas in Yunnan province and in realizing the sharing of high-quality educational resources. This research mainly adopts method of document investigation, which has investigated the construction situation of "Three Links and Two Platforms" in eight ethnic autonomous prefectures in Yunnan province in China including Chuxiong Yi Nationality Autonomous Prefecture, etc. The results show that the average value of the construction of "Three Links" is $63.55 \%, 14.75 \%$ and $9.00 \%$ respectively. "Two Platforms" mainly focus on public service platform for educational resources and public service platform for the construction of educational statistics, and the informatization of national education in Yunnan province should be improved greatly.
\end{abstract}

\section{Introduction}

In 2012, Conference on National Educational Informatization presented that in the period of "the 12th Five-Year Plan", we should focus on the construction of "Three Links and Two Platforms", accelerating the educational informatization and improving the educational development in rural areas as well as remote and border areas. "Three Links"refers to Campus Links to ICTs (Information and Communication Technologies), highquality resource of Class Links to ICTs, People Links to ICTs, and "Two Platforms" refers to public service platform for educational resources and public service platform for educational management. "Three Links and Two Platforms", the important content of China's National Educational Informatization Plan (2011-2020), has played active role in reforming and optimizing classroom teaching methods, increasing quality and efficiency of education and teaching, improving educational equality and accelerating educational modernization.

Located in frontier region of southwest in China, with complex terrain and a number of ethnic groups, the development of economy and education of Yunnan province is relatively slow. "Three Links and Two Platforms" has played a unique and important role in promoting educational equality in ethnic areas in Yunnan province and realizing wide sharing of high-quality educational resources, improving nationalities education quality and building learning-oriented society, promoting the reform of nationalities education concept and cultivating innovative talents. It is also the motivation and support of the accomplishment of the modernization of nationalities education in Yunnan province. Therefore, Yunnan province put the equipment of education informatization into supervision and evaluation index system for education research of County-level People's Government and put the construction and equipment situation of "three links two platform" into the key content of evaluating governments' resumptions. In particular, Yunnan province requires all ethnic autonomous prefectures to take full advantage of modern information technology, and pay attention to the deep integration of information technology and education. According to Three-year Plan for Informatization of Basic Education in Yunnan Province (2013-2015), until 2015, Yunnan province would have network teaching and learning environment, network learning spaces would cover all kinds of education and the high-quality educational resources would benefit to all minorities.

This research mainly focuses on the investigation of the construction situation of "Three Links and Two Platforms" in minority areas in Yunnan province in China. The result is not only helpful for Electrification Center of Yunnan Province to formulate educational resources construction program in minority areas, but also provide research references to accelerating the overall development of education in minority areas in Yunnan province.

\section{Research objects and methods}

\subsection{Research objects}

a Corresponding author: 1318581165@qq.com; cjyzhaozhilin@163.com 
Sixth census in Yunnan province shows that in the actual registered populations, minorities has a population of 15.337 million, accounting for $33.37 \%$ of the total. Thus, Yunnan province always attaches great importance to the nationalities education. The minorities in Yunnan province mainly live in Chuxiong Yi Autonomous Prefecture, Honghe Hani and Yi Autonomous Prefecture, Wenshan Zhuang and Miao Autonomous Prefecture, Xishuangbanna Dai Autonomous Prefecture, Dali Bai Autonomous Prefecture, Dehong Dai and Jingpo Autonomous Prefecture, Nujiang of the Lisu Autonomous Prefecture and Diqing Tibetan Autonomous Prefecture. The total areas of these eight autonomous prefectures almost take the half of the area of Yunnan province, and the main minorities are Yi nationality, Bai nationality, Hani nationality and Dai nationality. This research mainly investigates the practical application situation of "Three Links and Two Platforms" in the education bureau of Chuxiong City, Mengzi City, Wenshan City, Jinghong City, Dali City, Mang City, Lushui County and Shangri-La City.

\subsection{Research methods}

This research mainly adopts method of document investigation, which has investigated the construction situation of "Three Links and Two Platforms" in those eight ethnic autonomous prefectures in Yunnan province. The contents include visiting web portal of Yunnan Electronic Education, consulting "presentation of educational informatization" during 2011-2015, acquiring basic data of educational informatization of autonomous prefectures in "the percentage of network access in school", "the percentage of network access in class", "the percentage of network access of computer room in school" and "the percentage of link between teachers".

\section{Result and analysis}

Informatization of basic education is the footstone of improving the information quality of students in minority areas, and the most important thing to accelerate educational informatization in minority areas in Yunnan province. Minority areas in Yunnan province need to accelerate infrastructure construction of informatization of basic education, realize the four-level educational network system between province, state (city), county (city, district) and school, increase the number of computer for each students in every one hundred students in middle and primary schools, and equip more multimedia distance learning facilities for national middle and primary schools. In order to thoroughly implement Development Plan of Educational Informatization in Yunnan Province (20132015) and Three-year Plan for Informatization of Basic Education in Yunnan Province (2013-2015), all autonomous prefectures in Yunnan province take the construction of "Three Links and Two Platforms" as the main task of educational information construction. For this purpose, State Bureau of Educations such as Chuxiong are strengthening management of school education information and construction of school network and focus on the construction of "Three Links and Two Platforms" of educational informatization.

\subsection{Investigation and analysis of "Three Links"}

According to monthly report of work progress of educational informatization of all autonomous prefectures in July 2015, educational informatization in Yunnan province is still faced with some special difficulties and prominent problems, and the gap between the overall development level and national average level still exist, as illustrated in Table 1.

Table 1. Basic Statistics of educational information construction in major minority areas in Yunnan province

\begin{tabular}{|c|c|c|c|c|}
\hline $\begin{array}{l}\text { Major } \\
\text { minority } \\
\text { areas in } \\
\text { Yunnan } \\
\text { province } \\
\text { in China }\end{array}$ & $\begin{array}{l}\text { The } \\
\text { percentag } \\
\text { e of } \\
\text { Schools } \\
\text { links to } \\
\text { ICTs }\end{array}$ & $\begin{array}{l}\text { The } \\
\text { percenta } \\
\text { ge of } \\
\text { class } \\
\text { links to } \\
\text { ICTs }\end{array}$ & $\begin{array}{l}\text { The } \\
\text { percentage } \\
\text { of network } \\
\text { access of } \\
\text { computer } \\
\text { room in } \\
\text { school }\end{array}$ & $\begin{array}{l}\text { The } \\
\text { percentag } \\
\text { e of } \\
\text { teachers } \\
\text { links to } \\
\text { ICTs }\end{array}$ \\
\hline Chuxiong & $83.9 \%$ & $\begin{array}{c}10 \% \sim 20 \\
\%\end{array}$ & $20 \% \sim 30 \%$ & $1 \% \sim 10 \%$ \\
\hline Honghe & $\begin{array}{c}40 \% \sim 50 \\
\%\end{array}$ & $\begin{array}{c}10 \% \sim 20 \\
\%\end{array}$ & $30 \% \sim 50 \%$ & $\begin{array}{l}\text { No } \\
\text { statistics }\end{array}$ \\
\hline Wenshan & $70 \%$ & $25.78 \%$ & $30 \% \sim 50 \%$ & $10 \% \sim 20 \%$ \\
\hline $\begin{array}{c}\text { Xishuang } \\
\text { banna }\end{array}$ & $89.8 \%$ & $22.2 \%$ & $58.6 \%$ & $1 \% \sim 10 \%$ \\
\hline Dali & $75.09 \%$ & $\begin{array}{c}10 \% \sim 20 \\
\%\end{array}$ & $20 \% \sim 30 \%$ & 0 \\
\hline Dehong & & $<10 \%$ & $54.6 \%$ & 0 \\
\hline Nujiang & $31.6 \%$ & $<10 \%$ & $15 \% \sim 20 \%$ & $1 \% \sim 10 \%$ \\
\hline Diqing & $53 \%$ & $\begin{array}{c}10 \% \sim 20 \\
\%\end{array}$ & $15 \% \sim 20 \%$ & $42 \%$ \\
\hline Average & $63.55 \%$ & $14.75 \%$ & $34.78 \%$ & $9.00 \%$ \\
\hline
\end{tabular}

Data sources: Electrification Center of Yunnan Province; Report on the work progress of educational informatization in Yunnan province in July 2014 by Yunnan Provincial Department of Education

In order to act in the spirits of the Fifth Plenary Session of the 18th CPC Central Committee and accelerate to popularize information technology in primary and middle schools, the Ministry of Education decided to implement the project, "Schools Links to ICTs" in primary and middle schools and issued Notice on Implication of "Schools Links to ICTs" Project in Primary and Middle Schools in 2000. The goal of this project was that $90 \%$ primary and middle schools in China which are independently established can have access to the internet in 5-10 years. However, as is shown in Table 1, the proportion of "Schools Links to ICTs" (the proportion of access to campuses) in Xishuangbanna Dai Autonomous Prefecture is the highest, $89.8 \%$ and the lowest, Nujiang Lisu Autonomous Prefecture, $31.6 \%$, which is lower than the goal of $90 \%$. It was obvious that there were unbalanced allocation of basic resources in "Schools Links to ICTs". In the construction of high-quality resource of "Class Links to ICTs", 2922 compulsory education schools in Yunnan Province had built campus network by July 2014, accounting for $15.4 \%$ of the total number of compulsory education schools. The average value of "the proportion of access to class" in minority autonomous prefectures was $14.75 \%$, which was equal to the overall construction situation of the high-quality resource of "Class Links to ICTs" in Yunnan Province but it is still very low. Work 
Points of Education Informatization in 2015 of Ministry of Education required $50 \%$ teachers and $30 \%$ students who were at least senior high school students could have realname network learning space and the network learning space would be applied intensively in education and teaching. At present, Yunnan Provincial Audio-Visual Education Center only counts the proportion of "People Links to ICTs" of teachers, except that the proportion in Diqing Tibetan Autonomous Prefecture basically meet the standards, and the proportion for most teachers in other autonomous prefectures is not more than $10 \%$. Schools in Dali Bai Autonomous Prefecture and Dehong Dai and Jingpo Autonomous Prefecture haven't built the "People Links to ICTs", indicating that the construction and application of network learning space, "People Links to ICTs", in Yunnan Province has been in the initial stage.

\subsection{Research analysis of "Two Platforms"}

On the basis of National Public Platform of Educational Resources, Yunnan Province relies on the high-quality education resources of "Yunnan Distance Education Network", actively explores the resource sharing mechanism of "enterprises compete to offer, government assess to enter and schools self-determine to adopt", and vigorously promotes the exploration and research of teachers training, resources sharing, interactive teaching and other aspects. In 2014, Yunnan built the Yunnan Public Platform of Education Resources (YunJiao Cloud for short) so as to achieve the joint construction and sharing of Yunnan Province's quality education resources and meet the urgent needs of teachers and students in Yunnan Province toward quality education resources. In the meantime, YunJiao Cloud can effectively spread the advanced teaching ideas and methods, which helps solve the problem of "lack of teachers and few teaching materials" in many poor schools in Yunnan remote minority areas, comprehensively improve the teaching quality and promote the balanced development of education. As is shown in Table 2, according to the data of Yunnan Public Platform of Education Resources, by November 17, 2015, the total number of registration of minority autonomous prefectures is 92,957, accounting for $40.10 \%$ in the province; the total number of uploading teaching resources is 451 and the download times of resources is close to 200,000. The download times of resources in Chuxiong Yi Autonomous Prefecture ranks first in the province. According to the number of registered users, resources to be uploaded and download inYunJiao Cloud, it can be seen that the resource utilization of Yunnan minority autonomous prefectures is still in the early stage of resources sharing and the number of joint resources is very small.

Table 2. Statistics of public platforms of educational resources in Yunnan main ethnic regions

\begin{tabular}{|c|c|c|c|c|c|c|}
\hline \multirow[t]{2}{*}{ Minority areas } & \multicolumn{2}{|c|}{ Number of registered users } & \multicolumn{2}{|c|}{$\begin{array}{l}\text { Number of uploading } \\
\text { resources }\end{array}$} & \multicolumn{2}{|c|}{ Number of downloading resources } \\
\hline & Number & $\begin{array}{l}\text { Ranking in } \\
\text { Yunnan }\end{array}$ & Number & $\begin{array}{l}\text { Ranking in } \\
\text { Yunnan }\end{array}$ & Number & Ranking in Yunnan \\
\hline Chuxiong & 21,584 & 4 & 112 & 6 & 107,329 & 1 \\
\hline Honghe & 22,008 & 3 & 16 & 13 & 29,386 & 7 \\
\hline Wenshan & 16,333 & 8 & 93 & 7 & 12,930 & 12 \\
\hline Xishuangbanna & 7,056 & 11 & 22 & 12 & 4,249 & 14 \\
\hline Dali & 16,991 & 7 & 152 & 4 & 33,878 & 4 \\
\hline Dehong & 5,685 & 13 & 47 & 10 & 6,654 & 13 \\
\hline Nujiang & 1,129 & 17 & 7 & 16 & 2,718 & 16 \\
\hline Diqing & 2,171 & 16 & 2 & 17 & 1,545 & 17 \\
\hline Total number & \multicolumn{2}{|c|}{92,957} & \multicolumn{2}{|c|}{451} & \multicolumn{2}{|c|}{198,689} \\
\hline $\begin{array}{l}\text { Total number of } \\
\text { Yunnan Province }\end{array}$ & \multicolumn{2}{|c|}{231,818} & \multicolumn{2}{|c|}{1,416} & \multicolumn{2}{|c|}{404,697} \\
\hline $\begin{array}{c}\text { Proportion in } \\
\text { Yunnan Province }\end{array}$ & \multicolumn{2}{|c|}{$40.10 \%$} & \multicolumn{2}{|c|}{$31.85 \%$} & \multicolumn{2}{|c|}{$49.10 \%$} \\
\hline
\end{tabular}

Source: Yunnan Public Platform of Education Resources [EB / OL], Key Laboratory of Education Informatization for Nationalities (Yunnan Normal University), Ministry of Education, China

In China, speeding up education management informatization, well building the National Public Service Platform of Education Management and having a comprehensive command of the dynamic data of conditions for setting up schools in students, teachers and schools across the country is of great significance to improve the education service, support the scientific decision-making and strengthen the education management. The construction of Yunnan Education Data Center has made great strides and education management information system has been run smoothly since 2014, including "Management Information System for Primary and middle School Students' Status", "Students Financial
Management Information System", "Vocational School Student Management Information System", "Campus Security Management Information System" and other management systems. At the same time, the minority autonomous prefectures also actively built and run their public platform of educational resources according to their situations. For example, Work Points for National Pilot Urban Construction of Information Benefiting People in Wenshan pointed out the digitization for Students' Status files management would reach $100 \%$ and the public service for education management should be finished by the end of 2016; public platform of educational resources in Honghe had already been officially launched and run and in 2013, the online management for primary and middle school students 'status had been completed in Nujiang through which the information of the primary and middle school students in Nujiang, and had been input in Management 
Information System for National Primary and Middle School Students' Status and Management System of Academic Proficiency Examination in Yunnan Province.

\section{Conclusions}

In summary, the "Three Links and Two platforms" is the core objective and key project of the construction for national education informatization during the "Twelfth Five-Year Plan" in China. In Yunnan Province, eight ethnic autonomous prefectures have implemented the related work of "Three Links and Two Platforms". The construction and application of "Three Links" have been in the early stage. In the construction of "Two Platforms", YunJiao Cloud, as the main public platform of educational resources in Yunnan Province, has attracted more than 90,000 students from ethnic autonomous prefectures to register on, and the education resources has been downloaded nearly 20 million times. Furthermore, the public service platform of educational management should consist of three subsystems: information system for educational management, supporting system for educational decision-making and information system for education evaluation. Yunnan ethnic regions are mainly in the transition stage from information system for educational management to supporting system for educational decision-making and information system for education evaluation.

\section{Acknowlegement}

This work was supported by the National Soft Science Project of China under Grant No. 2013GXS4D149, Education Humanities and Social Sciences Research Project of Ministry of Education in China under Grant No. 12YJCZH053 and Yunnan Science and Technology Development Strategy and Policy Research Project in China under Grant No. 2014RD029.

\section{References}

1. Zhu Zhiting, Guan Jueqi. Construction Framework of "Network Learning Space: People Access to ICTs". China Educational Technology, 10, (2013).

2. Yunnan Provincial Bureau of Statistic. Data Bulletin of Yunnan's Sixth National Census [Z].2011-05-09.

3. Yunnan Provincial Audio - Visual Education Center. Notice on the Yunnan Provincial Progress of Education Informationization of Yunnan Education in July, 2014 [Z]. 2014-07-30.

4. Yunnan Public Platform of Education Resources [EB/OL].

5. Yan Qichao, Zhou Xuehe. Education of Ethnic Minorities in Xinjiang from the Angle of Three Links \& Two Platforms. China Educational Technology, 9, (2014).

6. Wang Ane. Technological Changes Education: Research on the Construct Model of the Informatization Environment in the Border Ethnic Schools of Yunnan, Chengdu, Southwest University, (2014).

7. Zhu Jingjing. Research on Sharing Strategy of Cultural Informationization Resources between Schools and Community in Frontier Nationality Areas of Yunnan Province. Chengdu, Southwest University (2014).

8. Jiao Jianli. An Informal Talk on "Two Platforms" of "Three Accesses and Two Platforms". China Information and Technology, 11, (2013).

9. Wei Jian. The Culture, "Fusion· Harmony", Leads the Construction of Schools with Ethnic Characteristics. China Nationalities Education, 1, (2015).

10. Chu Zhuwu, Mo Hongmei, An Analysis of Ethnic Cultural Construction in the Early Period of New China. Journal of Beijing University of Nationalities, 5, (2012) 